Biological and Clinical Sciences Research Journal

ISSN: 2708-2261

www.bcsrj.com

DOI: https://doi.org/10.54112/bcsri.v2021i1.59

Biol. Clin. Sci. Res. J., Volume, 2020: 59

MEDEYE

Original Research Article

\title{
PLACENTAL THICKNESS AND ITS CORRELATION TO GESTATIONAL AGE ESTIMATED BY FOETAL GROWTH PARAMETERS-A CROSS SECTIONAL ULTRASONOGRAPHIC STUDY
}

\author{
AHMAD M*1, ANJUM MN ${ }^{2}$, ASIF $\mathbf{M}^{3}$, AYUB $\mathbf{S}^{* 4}$, MUZAFFAR ${ }^{1}$, MUBEEN I ${ }^{2}$ \\ ${ }^{1}$ Social Security Teaching Hospital, Multan Road, Lahore, Pakistan \\ ${ }^{2}$ Radiology Research Section, The University of Lahore, Lahore, Pakistan \\ ${ }^{3}$ UIPT, The University of Lahore, , Lahore, Pakistan \\ ${ }^{4}$ Department of Gynecology and Obstetrics, Hameed Latif Hospital, Lahore, Pakistan \\ *Corresponding author email: drahmad6666@gmail.com, drsadafahmad6@gmail.com
}

(Received, $4^{\text {th }}$ December 2020, Revised $21^{\text {th }}$ March 2021, Published $27^{\text {th }}$ March 2021)

\begin{abstract}
The placenta is a meterno-fetal organ and starts developing on the 5th week from chorionic villi at the implantation site. The placenta continues to increase in thickness and hence its thickness can be used to indicate the gestational age when the last menstruation date is not confirmed. The purpose of the study was to find out the correlation of placental thickness to the gestational age estimated by growth parameters of the fetus. The study was a cross-sectional analytical study conducted on 2000 participants. The study was conducted in the Department of Radiology Social Security Hospital, Multan Chungi Lahore. The inclusion-exclusion criteria were established and participants were observed using a Toshiba ultrasonography machine. The subjects were placed supine and placental thickness was measured to the accuracy of $1 \mathrm{~mm}$. Pearson's correlation was applied to find out the correlation between placental thickness and gestational age of the participants. The mean age of the participants was $28.37 \pm 4.6$. The youngest participant was age 18 and the eldest participant was age 40. The gestational age of the participants included ranged between 12th week to 40th week. Pearson's correlation score indicated that the correlation value 0.896. Which indicated that the placental thickness and gestational age were strongly correlated? The P-value $<0.05$ indicated that the results were significant. The study concluded a strong correlation between gestational age and placental thickness of the fetus. The thickness of the placenta increased with an increase in gestational age and hence could be used as a predictor and a parameter of gestational age prediction when the last menstruation is uncertain or is unknown.
\end{abstract}

Keywords: placental thickness, radiology, immunological functions, gestational age, correlation

there may be a change in the shape of the foetal head

\section{Introduction}

Placenta is a discoid shaped fetal organ that exhibits important metabolic and endocrine, immunological functions. It provides a physiological link between mother and fetus and serves as a passage for nutrition and respiration (Robinson and Alasia Osuoabo, 2019). The placenta starts developing on $5^{\text {th }}$ week from the chorionic villi at the site of implantation and by $9^{\text {th }}$ to $10^{\text {th }}$ week can be seen through ultrasound. At $16^{\text {th }}$ week the placenta reaches its ultimate thickness and continues to grow in diameter until the end of the third trimester (Khalid, 2009). Foetal growth parameters such as biparietal diameter (BPD), head circumference (HC), abdominal circumference (AC) and femoral length (FL) are used to sonologically estimate foetal weight (Karthikeyan et al., 2012a). In circumstances when these parameters can't be identified the estimation of placental age becomes a problem. In conditions such as the rupture of membrane, breech presentation, multiple gestation and BPD cannot be accurately measured (Noor et al., 2018). Placental thickness can be used as a parameter for estimation of gestational age, as it can be measured without much difficulty. Placenta is relatively immobile as compared to the fetus while doing an ultrasound. It is the only factor that is independent of the foetus for prediction of gestational age (Mahale et al., 2018). Estimation of exact fetal age is essential for prediction of time of delivery and prompt picking of any antenatal anomaly. Since years prediction of gestational age is relied on the last menstrual period date, however according to literature only $56 \%$ of the females are able to retrieve the last menstrual period date with complete certainty. If uncomplicated this forgetfulness might not cost much, but in complicated pregnancies knowledge of accurate fetal age is crucial. Addition of placental thickness as a marker of fetal age and growth parameters will add to the safety of mother and child. Hence this study will be conducted to find

[Citation: Ahmad, M., Anjum, M.N., Asif, M., Ayub, S., Muzffar, A., Mubeen, I., (2021). Placental thickness and its correlation to gestational age estimated by foetal growth parameters-a cross sectional ultrasonographic study. Biol. Clin. Sci. Res. J., 2021: 59. doi: https://doi.org/10.54112/bcsrj.v2021i1.59] 
out the correlation of placental thickness with fetal age and growth parameters.

\section{Methodology}

This cross sectional analytical study was conducted at the Department of Radiology Social Security Hospital, Multan Chungi Lahore. The sample size was fixed to 2000 using $95 \%$ of level of significance, $60 \%$ power of test and $5 \%$ margin of error. The non-probability consecutive sampling technique was used to collect the required sample. Inclusion criteria for the study was as follows; Singleton pregnancies, 11-40 weeks, the known last menstrual period, a history of regular menstruation. Whereas the exclusion criteria was as follows; Maternal Disease e.g. gestational diabetes, hypertension (Systemic hypertension and Pregnancy induced hypertension), Anaemia, Foetal anomalies, palcenta previa, placental anomalies and poor visualization of the placenta, Multiple pregnancies and last menstrual period not known or irregular menstrual periods (Karthikeyan et al., 2012a). Toshiba Ultrasonography machine was used to examine the subjects. Each foetus was measured only once during the whole study. The transabdominal scanner was used to find out the foetal anomaly if there is any. The gestational age was determined by measuring the biparietal diameter, the abdominal circumference, the crown rump length, the head circumference and the femur length. The placental thickness was measured at the level of the umbilical cord insertion; the maximum thickness was noted in the cross section. Each placenta was measured to a $1 \mathrm{~mm}$ precision, at its greatest thickness, which is perpendicular to the uterine wall. The uterine myometrium and the retroplacental veins were excluded. The subjects were positioned supine and full bladder was ensured at the time of taking measurements. The rules and regulations devised by ethical committee of University of Lahore were followed while conducting the study and rights of the subjects were respected. Written informed consent was signed by all the participants and all the confidentiality of the gathered data was ensured. The subjects were informed that the study procedure includes no harm to them and is a part of regular examination. Subjects were moreover informed that they were free to withdraw at any time during the process of the study. Data in laptop was kept under password. After obtaining the informed consent patients were enrolled in the study. Demographic data was collected prior conducting the required examinations. Ultrasonographic measurements of fetal growth parameters i.e. femur length, biparietal diameter, head circumference, abdominal circumference were taken and compared to the placental thickness. All data collected was mentioned in a questionnaire. Data was analysed using SPSS version 21. Quantitative variables were described as mean and SD. Whereas qualitative variables were described as frequency and percentage and Pearson's correlation was calculated to find-out the relationship between placental thickness and gestational age estimated by fetal growth parameters. $\mathrm{P}$-value $\leq 0.05$ will be taken as significant.

\section{Results}

The data comprised of 2000 women. Mean age \pm S.D of the participants were $28.37 \pm 4.69$. The youngest participant was of age 18 and the eldest participant was of age 40. Biparietal diameter, abdominal circumference, femur length and head circumference was measured to calculate the gestational age and the results were correlated with placental thickness to estimate the gestational age. The mean results of growth parameters were as follows; Biparietal diameter $76.59 \pm 17.60$, abdominal circumference $268.42 \pm 91.48$, femur length $59.30 \pm 15.74$, head circumference $280.11 \pm 61.69$, placental thickness $31.03 \pm 6.83$. The maximum gestational age of the participants was 40 weeks and the minimum gestational age of the participants was 12 weeks. The mean gestational age of the participants was $30.98 \pm$ 6.64 weeks. The correlation between placental thickness and gestational age was calculated using Pearson's correlation and the correlation score of 0.896 indicated a strong correlation between placental thickness and gestational age. The positive value indicated that placental thickness increased as gestational age increased. Moreover, the $\mathrm{P}$ value $\leq$ 0.05 indicated that the results of the Pearson's correlation were significant (Table 4).

Table 1: Mean Placental thickness during first trimester of pregnancy $\left(12^{\text {th }}\right.$ and $13^{\text {th }}$ week)

\begin{tabular}{lll}
\hline $\begin{array}{l}\text { Gestational } \\
\text { Week }\end{array}$ & $\begin{array}{l}\text { Number of } \\
\text { Subjects }\end{array}$ & $\begin{array}{l}\text { Mean Placental } \\
\text { Thickness }\end{array}$ \\
\hline $12^{\text {th }}$ & 7 & $11.42 \pm 9.03$ \\
$13^{\text {th }}$ & 15 & $13.33 \pm 1.68$ \\
\hline
\end{tabular}

Table 2: Mean Placental thickness during second trimester of pregnancy $\left(14^{\text {th }}\right.$ to $26^{\text {th }}$ week)

\begin{tabular}{lll}
\hline $\begin{array}{l}\text { Gestational } \\
\text { Week }\end{array}$ & $\begin{array}{l}\text { Number of } \\
\text { Subjects }\end{array}$ & $\begin{array}{l}\text { Mean Placental } \\
\text { Thickness }\end{array}$ \\
\hline $14^{\text {th }}$ & 26 & $14.42 \pm 2.50$ \\
$15^{\text {th }}$ & 11 & $16.90 \pm 3.98$ \\
$16^{\text {th }}$ & 20 & $16.55 \pm 1.66$ \\
$17^{\text {th }}$ & 12 & $17.00 \pm 2.13$ \\
\hline
\end{tabular}

[Citation: Ahmad, M., Anjum, M.N., Asif, M., Ayub, S., Muzffar, A., Mubeen, I., (2021). Placental thickness and its correlation to gestational age estimated by foetal growth parameters-a cross sectional ultrasonographic study. Biol. Clin. Sci. Res. J., 2021: 59. doi: https://doi.org/10.54112/bcsrj.v2021i1.59] 


\begin{tabular}{lll}
\hline $18^{\text {th }}$ & 51 & $18.76 \pm 2.86$ \\
$19^{\text {th }}$ & 30 & $19.23 \pm 2.95$ \\
$20^{\text {th }}$ & 36 & $19.77 \pm 2.41$ \\
$21^{\text {st }}$ & 37 & $22.25 \pm 3.52$ \\
$22^{\text {nd }}$ & 39 & $22.97 \pm 2.89$ \\
$23^{\text {rd }}$ & 42 & $24.66 \pm 3.25$ \\
$24^{\text {th }}$ & 17 & $23.41 \pm 2.00$ \\
$25^{\text {th }}$ & 25 & $25.16 \pm 2.71$ \\
$26^{\text {th }}$ & 34 & $26.08 \pm 2.47$ \\
\hline
\end{tabular}

Table 3: Mean Placental thickness during second trimester of pregnancy $\left(27^{\text {th }}\right.$ to $40^{\text {th }}$ week $)$

\begin{tabular}{lll}
\hline $\begin{array}{l}\text { Gestational } \\
\text { Week }\end{array}$ & $\begin{array}{l}\text { Number of } \\
\text { Subjects }\end{array}$ & $\begin{array}{l}\text { Mean Placental } \\
\text { Thickness }\end{array}$ \\
\hline $27^{\text {th }}$ & 56 & $26.78 \pm 2.95$ \\
$28^{\text {th }}$ & 56 & $27.96 \pm 2.62$ \\
$29^{\text {th }}$ & 93 & $29.35 \pm 2.67$ \\
$30^{\text {th }}$ & 73 & $30.04 \pm 3.38$ \\
$31^{\text {st }}$ & 99 & $31.32 \pm 2.38$ \\
$32^{\text {nd }}$ & 125 & $32.88 \pm 2.62$ \\
$33^{\text {rd }}$ & 156 & $33.09 \pm 2.87$ \\
$34^{\text {th }}$ & 206 & $34.03 \pm 2.83$ \\
$35^{\text {th }}$ & 184 & $35.18 \pm 2.50$ \\
$36^{\text {th }}$ & 166 & $35.65 \pm 3.19$ \\
$37^{\text {th }}$ & 193 & $36.48 \pm 3.13$ \\
$38^{\text {th }}$ & 116 & $36.93 \pm 3.76$ \\
$39^{\text {th }}$ & 59 & $38.30 \pm 4.49$ \\
$40^{\text {th }}$ & 06 & $37.16 \pm 2.40$ \\
\hline
\end{tabular}

Table 4: Correlation between Placental Thickness and Gestational Age

Correlation between Placental Thickness and Gestational Age

\begin{tabular}{|c|c|c|c|}
\hline & & $\begin{array}{l}\text { Placental } \\
\text { thickness }\end{array}$ & $\begin{array}{c}\text { Gestational } \\
\text { Age }\end{array}$ \\
\hline \multirow[t]{3}{*}{$\begin{array}{l}\text { Placental } \\
\text { thickness }\end{array}$} & $\begin{array}{l}\text { Pearson } \\
\text { Correlation }\end{array}$ & 1 & $0.896^{* * *}$ \\
\hline & $\begin{array}{l}\text { Sig. (2- } \\
\text { tailed) }\end{array}$ & & 0.000 \\
\hline & $\mathrm{N}$ & 2000 & 2000 \\
\hline \multirow{4}{*}{$\begin{array}{l}\text { Gestational } \\
\text { Age }\end{array}$} & Pearson & $0.896^{* *}$ & 1 \\
\hline & Correlation & & \\
\hline & $\begin{array}{l}\text { Sig. (2- } \\
\text { tailed) }\end{array}$ & 0.000 & \\
\hline & $\mathrm{N}$ & 2000 & 2000 \\
\hline
\end{tabular}

\section{Discussion}

Placental thickness can be an accurate predictor of fetal growth and any retardation in growth or early termination may be estimated by it. Any abnormality at fetal level can be timely detected with the help of defined placental thickness at any stage. It in this way can predict the abnormality when it is absent clinically or symptomatically. Placenta is a maternofetal organ and exhibits important metabolic, immunological, thermoregulatory and endocrine functions. The formation of placenta begins on $5^{\text {th }}$ week from chorionic villi at implantation site and completes by $16^{\text {th }}$ week. Placenta is present in pebble grey color between week 8 and 20 of pregnancy and achieves maximum growth at the term. Being a materno-fetal organ its health indicates the health of fetus. After being detectable at $8^{\text {th }}$ week the placenta corresponds to the gestational age in weeks. Form current study the placental thickness was measured at the level of umbilical cord insertion (BaGhel et al., 2015). In current study the relationship between placental thickness and gestational age was found to be linear. the results were consistent with the study by Naik and his colleagues (Naik et al., 2021) placental thickness increased with the increase in gestational age and increase in thickness was observed in different participants presenting with different trimesters i.e. week 12 to 39 . In first trimester i.e. $12^{\text {th }}$ week the mean placental thickness was $11.42 \pm 9.03$ which reached $13.33 \pm 1.68$ at $13^{\text {th }}$ week. In $2^{\text {nd }}$ trimester the placental thickness was observed to be $14.42 \pm 2.50$ at earliest i.e. $14^{\text {th }}$ week and reached to the thickness of $26.08+2.47$ at the end of $2^{\text {nd }}$ trimester i.e. $26^{\text {th }}$ week. The placental thickness in the start of $3^{\text {rd }}$ trimester i.e. $27^{\text {th }}$ week was observed to be $26.78 \pm 2.95$ which increased to $38.30 \pm 4.49$ at $39^{\text {th }}$ week. An increase of $13 \mathrm{~mm}$ in the thickness of placenta was observed in $1^{\text {st }}$ trimester, increase of $12 \mathrm{~mm}$ in thickness of placenta was observed in $2^{\text {nd }}$ trimester whereas in $3^{\text {rd }}$ trimester the increase in placental thickness was observed to be $10 \mathrm{~mm}$. this indicated that the growth rate of placenta was fastest in $1^{\text {st }}$ trimester and it slowed down in $3^{\text {rd }}$ trimester. The placental thickness started decreasing after $39^{\text {th }}$ week of pregnancy as was observed in current study. The mean placental thickness at $39^{\text {th }}$ week was $38.30 \pm 4.49$ which decreased to $37.16 \pm$ 2.40 at $40^{\text {th }}$ week. The decline in placental thickness was consistent with the previously conducted studies however the previously conducted studies reported the decline in placental thickness to start after $36^{\text {th }}$ week of pregnancy (Naik et al., 2021) whereas in current study placenta continued to grow in thickness (although with decreased rate) until $39^{\text {th }}$ week. Placental thickness was not considered with the location of placenta as the attachment site of placenta according to Kaushal et al does not determine the thickness of placenta. A similar study was conducted by Karthikeyan et al and they concluded that below normal thickness of placenta for gestational age may be an indicator of a clinical condition and hence

[Citation: Ahmad, M., Anjum, M.N., Asif, M., Ayub, S., Muzffar, A., Mubeen, I., (2021). Placental thickness and its correlation to gestational age estimated by foetal growth parameters-a cross sectional ultrasonographic study. Biol. Clin. Sci. Res. J., 2021: 59. doi: https://doi.org/10.54112/bcsrj.v2021i1.59] 
should be checked (Karthikeyan et al., 2012b). Similarly thick placenta is related with adverse outcomes (Miwa et al., 2014). Placental growth corresponds effectively for $2^{\text {nd }}$ and $3^{\text {rd }}$ trimesters (Pant and Dashottar, 2017). The placental thickness corresponded to gestational age more specifically between $12^{\text {th }}$ to $26^{\text {th }}$ week of fetal life. The results were consistent with the study conducted by Suresh et al in 2017, according to their results placental growth was consistent with gestational age during $12^{\text {th }}$ to $24^{\text {th }}$ week of fetal life. Placental thickness can be related to the chromosomal abnormalities (Hafner et al., 2001) a study conducted by a study conducted by Dombrowski et al (1992) indicated that the placental thickness may falsely increase and decrease in polyhydramnios and oligohydramnios respectively (Dombrowski et al., 1992). In current study correlation between placental thickness was estimated and a strong correlation was observed. The Pearson's correlation value of 0.896 indicated that there was a strong correlation between placental thickness and gestational age. The increase in thickness of placenta was consistent with the increase in gestational age. The results were consistent with the results of the study conducted by Adhikari et al in 2015 who observed a linear correlation between the gestational age and placental thickness(Adhikari et al., 2015). The placental thickness hence can be used to predict the gestational age when the duration of pregnancy is not known or is uncertain.

\section{Conclusion}

The study concluded a strong correlation between gestational age and placental thickness of the fetus. The thickness of the placenta increased with increase in gestational age and hence could be used as a predictor and a parameter of gestational age prediction when the last menstruation is uncertain or is unknown.

\section{Conflict of interest}

The authors declared absence of conflict of interest.

\section{References}

Adhikari, R., Deka, P. K., Tayal, A., and Chettri, P. K. J. L. (2015). Ultrasonographic Evaluation of Placental Thickness in Normal Singleton Pregnancies for Estimation of Gestation Age. 11, 7.0.

BaGhel, P., Bahel, V., Paramhans, R., Sachdev, P., Onkar, S. J. I. J. o. N. M., and Research (2015). Correlation of placental thickness estimated by ultrasonography with gestational age and fetal outcome. 3, 19-24.

Dombrowski, M., Wolfe, H., Saleh, A., Evans, M., O'Brien, J. J. U. i. O., Obstetrics, G. T. O. J. o. t. I. S. o. U. i., and Gynecology (1992). The sonographically thick placenta: a predictor of increased perinatal morbidity and mortality. 2, 252-255.

Hafner, E., Metzenbauer, M., Dillinger-Paller, B., Hoefinger, D., Schuchter, K., Sommer-Wagner, H., and Philipp, K. J. P. (2001). Correlation of first trimester placental volume and second trimester uterine artery Doppler flow. 22, 729734.

Karthikeyan, T., Subramaniam, R. K., Johnson, W., and Prabhu, K. (2012a). Placental thickness \& its correlation to gestational age \& foetal growth parameters-a cross sectional ultrasonographic study. Journal of clinical and diagnostic research: JCDR 6, 1732.

Karthikeyan, T., Subramaniam, R. K., Johnson, W., Prabhu, K. J. J. o. c., and JCDR, d. r. (2012b). Placental thickness \& its correlation to gestational age \& foetal growth parameters-a cross sectional ultrasonographic study. 6, 1732.

Khalid, M. I. (2009). ULTRASONOGRAPHIC CRITERIA FOR CORRELATION BETWEEN GESTATIONAL AGE AND PLACENTAL THICKNESS, sudan university of science and technology.

Mahale, N., Mitra, M., Mahale, A., Fernandes, M., and Ullal, S. (2018). Placental thickness and its correlation with gestational age and foetal growth parameters. GIORNALE ITALIANO DI OSTETRICIA E GINECOLOGIA 40, 33-41.

Miwa, I., Sase, M., Torii, M., Sanai, H., Nakamura, Y., and Ueda, K. J. S. (2014). A thick placenta: a predictor of adverse pregnancy outcomes. 3, $1-4$.

Naik, S. C., Dcuz, D. D. J. J. E. J. o. M., and Medicine, C. (2021). Placenta Thickness and Its Maturity in Terms of Gestational Age Based On USG. 7, 2545-2549.

Noor, N., Jain, A., Parveen, S., and Ali, S. M. J. I. J. R. C. O. G. (2018). Ultrasonographic measurement of placental thickness and its correlation with estimated fetal weight. 7, 287290.

Pant, S., and Dashottar, S. J. I. J. o. A. i. M. (2017). A correlative study to evaluate the gestational age by sonological measurement of placental thickness in normal second and third trimester pregnancy. 4, 1638-44.

Robinson, E. D., and Alasia Osuoabo, S. (2019). Foetal weight determination using sonographic measurement of placenta thickness. The Nigerian Health Journal 18, 45-53.

[Citation: Ahmad, M., Anjum, M.N., Asif, M., Ayub, S., Muzffar, A., Mubeen, I., (2021). Placental thickness and its correlation to gestational age estimated by foetal growth parameters-a cross sectional ultrasonographic study. Biol. Clin. Sci. Res. J., 2021: 59. doi: https://doi.org/10.54112/bcsrj.v2021i1.59] 


\section{(c) (i) \$}

Open Access This article is licensed under a Creative Commons Attribution 4.0 International License, which permits use, sharing, adaptation, distribution and reproduction in any medium or format, as long as you give appropriate credit to the original author(s) and the source, provide a link to the Creative Commons licence, and indicate if changes were made. The images or other third party material in this article are included in the article's Creative Commons licence, unless indicated otherwise in a credit line to the material. If material is not included in the article's Creative Commons licence and your intended use is not permitted by statutory regulation or exceeds the permitted use, you will need to obtain permission directly from the copyright holder. To view a copy of this licence, visit http://creativecommons.org/licen ses/by/4.0/.

(C) The Author(s) 2021

[Citation: Ahmad, M., Anjum, M.N., Asif, M., Ayub, S., Muzffar, A., Mubeen, I., (2021). Placental thickness and its correlation to gestational age estimated by foetal growth parameters-a cross sectional ultrasonographic study. Biol. Clin. Sci. Res. J., 2021: 59. doi: https://doi.org/10.54112/bcsrj.v2021i1.59] 